\title{
Use of Ambulatory Electrocardiography for the Detection of Paroxysmal Atrial Fibrillation in Patients with Stroke
}

\author{
Chaim Bell, Moira Kapral, with The Canadian Task Force on Preventive Health Care
}

\begin{abstract}
Background: Patients with stroke commonly undergo investigations to determine the underlying cause of stroke. These investigations often include ambulatory electrocardiography to detect paroxysmal atrial fibrillation. There is conflicting evidence in the literature regarding whether routine ambulatory electrocardiography should be performed in all or selected stroke patients. This paper reviews the available evidence on (1) the yield of ambulatory electrocardiography in detecting paroxysmal atrial fibrillation in patients with stroke or transient ischemic attack and (2) the effectiveness of anticoagulation in preventing recurrent stroke in patients with paroxysmal atrial fibrillation. Methods: A MEDLINE search for primary articles was performed, and the references were reviewed manually. In addition, citations were obtained from experts. The evidence was systematically reviewed using the evidence-based methodology of the Canadian Task Force on Preventive Health Care. Results: Ambulatory electrocardiography can detect atrial fibrillation not found on initial electrocardiogram in between $1 \%$ and $5 \%$ of people with stroke. Ambulatory electrocardiography is generally safe. The risk of recurrent stroke in the setting of paroxysmal atrial fibrillation is uncertain, but appears to be similar to that seen with chronic atrial fibrillation (about $12 \%$ per year). Therapy with warfarin may reduce this risk by about two-thirds as compared to placebo. The annual risk of major bleeding with warfarin therapy is between $1 \%$ and $3 \%$ but rates for individual patients depend on various specific risk factors. Interpretation: There is insufficient evidence to recommend for or against the use of ambulatory electrocardiography for the detection of paroxysmal atrial fibrillation in either selected or unselected patients with stroke (C Recommendation). There is fair evidence to recommend therapy with warfarin for patients with stroke and paroxysmal atrial fibrillation (B Recommendation).
\end{abstract}

RÉSUMÉ: Électrocardiographie ambulatoire pourla détection de la fibrillation auriculaire paroxystique chez les patients ayant subi un AVC. Introduction: Les patients ayant subi un AVC sont couramment investigués pour déterminer la cause de l'AVC. Ces investigations incluent souvent un enregistrement électrocardiographique ambulatoire pour détecter une fibrillation auriculaire paroxystique. Il existe des données conflictuelles dans la littérature concernant l'utilisation de routine de l'électrocardiographie ambulatoire chez tous les patients ayant subi un AVC ou chez des cas particuliers. Nous revoyons les données disponibles sur 1) le taux de détection de la fibrillation auriculaire paroxystique par électrocardiographie ambulatoire chez les patients ayant subi un AVC ou une ischémie transitoire et 2) l'efficacité de l'anticoagulation dans la prévention d'une récidive de l'AVC chez les patients qui ont une fibrillation auriculaire paroxystique. Méthodes: Une recherche d'articles dont c'était le sujet principal dans MEDLINE a été effectuée et les références ont été révisées manuellement. De plus, l'opinion d'experts dans le domaine a été obtenue. Les observations ont été révisées systématiquement en utilisant la méthodologie basée sur des données probantes du Groupe de travail Canadien sur les soins de santé préventifs. Résultats: L'électrocardiographie ambulatoire peut détecter une fibrillation auriculaire qui n'a pas été détectée à l'électrocardiogramme initial chez $1 \%$ à $5 \%$ des patients ayant subi un AVC. L'électrocardiographie ambulatoire est généralement sécuritaire. Le risque pour le patient de présenter un nouvel AVC dans le contexte de la fibrillation auriculaire paroxystique est incertain, mais il semble identique au risque observé dans la fibrillation auriculaire chronique (environ $12 \%$ par année). Le traitement par la warfarine peut diminuer ce risque d'à peu près les deux tiers comparé au placebo. Le risque annuel de saignement majeur sous traitement par la warfarine est de $1 \%$ à $3 \%$, mais le taux individualisé dépend de différents facteurs de risque spécifiques. Interprétation: Il n'existe pas suffisamment de données pour recommander ou ne pas recommander l'électrocardiographie ambulatoire pour la détection de la fibrillation auriculaire paroxystique chez des patients choisis ou non, ayant subi un AVC (recommandation de catégorie C). Il existe des données suffisantes pour recommander l'administration de warfarine chez les patients qui ont subi un AVC et qui font de la fibrillation auriculaire paroxystique (recommandation de catégorie B).

Can. J. Neurol. Sci. 2000; 27: 25-31

Stroke is a leading cause of mortality in Canada. ${ }^{1}$ It is a common and debilitating condition, particularly in those over age $65 .^{2}$ It is responsible for long hospital stays and its survivors often require long-term care placement or assistance with activities of daily living. ${ }^{1,3}$ The cost of acute and long-term care for patients with stroke is estimated at greater than $\$ 2.5$ billion per year in Canada. ${ }^{4}$

Stroke registries and population studies report that cardio-
From the Department of Medicine, University of Toronto, Institute of Medical Science, Program in Clinical Epidemiology and Health Services Research (C.B.) and the Department of Medicine, University of Toronto, Division of General Internal Medicine and Clinical Epidemiology, University Health Network, Toronto, Canada and the Institute for Clinical and Evaluative Sciences (M.K.) RECEIVED JUNE 29, 1999. ACCEPTEDINFINALFORMNOVEMBER 8, 1999. Reprint requests to: C. Bell, Canadian Task Force on Preventive Health Care, 801 Commissioners Rd. East, London, Ontario, N6C 5J1 
genic embolism accounts for about $15 \%$ (range, $6 \%$ to $23 \%$ ) of ischemic strokes and $15 \%$ of transient ischemic attacks. ${ }^{5-8}$ Cardioembolic stroke, which is defined as "the presence of a potential cardioembolic source in the absence of cerebrovascular disease in patients with nonlacunar stroke", is a heterogeneous entity, comprising multiple contributing disorders. Atrial fibrillation, a common condition found in almost $3 \%$ of the population, ${ }^{9}$ accounts for between $6 \%$ and $24 \%$ of all ischemic strokes and about one half of all cardioembolic strokes. ${ }^{5-8,10}$ The Framingham Study and retrospective reviews have found that paroxysmal or intermittent atrial fibrillation accounts for between $14 \%$ and $24 \%$ of strokes associated with atrial fibrillation and likely precedes the event. ${ }^{11-14}$ However, there are significant limitations to accurately determining the frequency and establishing the causes of cardioembolic stroke, as no criterion standard exists for its diagnosis. Often, patients will have both cerebrovascular disease and a potential cardioembolic source of emboli, and it may not be possible to determine the true cause of stroke in an individual patient. ${ }^{5,15}$

The mechanism of stroke should be identified in any individual patient, since the optimal therapy for secondary stroke risk reduction may vary with the underlying cause of stroke. ${ }^{5-8,10}$ Investigations for the cause of stroke typically include a patient history, physical examination, 12-lead electrocardiogram, laboratory tests, computed tomography of the brain, carotid artery imaging, and an echocardiogram (transthoracic or transesophageal). A 24-hour ambulatory continuous electrocardiogram is often obtained to search for an occult arrhythmia, the most common of which is paroxysmal atrial fibrillation. If found, paroxysmal atrial fibrillation may be an indication for treatment with anticoagulant medications to reduce the risk of subsequent stroke.

The evidence for the use of ambulatory continuous electrocardiography to identify a stroke patient with transient or paroxysmal atrial fibrillation that would not have been identified on initial testing will be evaluated in this paper. This manuscript will review and make recommendations regarding the available evidence on (1) the yield of ambulatory continuous electrocardiography in identifying paroxysmal or occult atrial fibrillation in stroke patients, and (2) the effectiveness of therapy for secondary stroke prophylaxis in patients with paroxysmal atrial fibrillation.

\section{METHODS}

After developing the causal pathway, evidence for each component was identified by an electronic literature search of MEDLINE (1966 to June 1999) using the MeSH terms "cerebrovascular disorders", "atrial fibrillation", "electrocardiography, ambulatory", "electrocardiography", "monitoring, physiologic", "diagnosis", "prevention", "research design", "therapy", "cohort studies", and "clinical trials". A professional librarian reviewed the search strategy. A manual review of references cited in these studies was also performed. Citations from experts and guidelines were obtained. Studies published in manuscript or abstract form in peer-reviewed journals were included. Both English and non-English language articles with English abstracts were considered. Studies were included if patients suffered a stroke or transient ischemic attack, had continuous electrocardiography performed, and if the presence or absence of chronic or paroxysmal atrial fibrillation was recorded.

This evidence was systematically reviewed using the methodology of the Canadian Task Force on Preventive Health Care. The Task Force of expert clinician/methodologists from a variety of medical specialties used a standardized evidencebased method for evaluating the effectiveness of this intervention. A manuscript providing critical appraisal of the evidence was prepared by the lead authors. This included identification and critical appraisal of key studies, and ratings of the quality of this evidence using the Task Force's established methodological hierarchy (Appendix 1), resulting in a summary of proposed conclusions and recommendations for consideration by the Task Force. This manuscript was pre-circulated to the members in April 1998 and evidence for this topic was presented by the lead authors and deliberated upon at a Task Force meeting in May 1998.

At the meeting, the expert panelists addressed critical issues, clarified ambiguous concepts and analysed the synthesis of the evidence. At the end of this process, the specific clinical recommendations proposed by the lead author were discussed, as were issues related to clarification of the recommendations for clinical application, and any gaps in evidence. The results of this process are reflected in the description of the decision criteria presented with the specific recommendations. The final decisions on recommendations were arrived at unanimously by the group and lead authors.

Subsequent to the meeting, the lead authors revised the manuscript accordingly. After final revision, the manuscript was sent by the Task Force to two experts in the field (identified by Task Force members at the meeting). Feedback from these experts was incorporated into a subsequent draft of the manuscript, which was then submitted to this Journal.

Procedures to achieve adequate documentation, consistency, comprehensiveness, objectivity and adherence to the Task Force methodology were maintained at all stages during review development, the consensus process, and beyond. These were managed by the Task Force Office, under supervision of the Chair, and ensured uniformity and impartiality throughout the review process. The full methodology has previously been described. ${ }^{16}$

\section{RESUlts}

\section{Stroke Risk}

\section{Chronic Atrial Fibrillation}

Patients with atrial fibrillation are at an increased risk for cerebral embolism. The magnitude of this risk depends upon the cause of the arrhythmia (e.g. mitral stenosis), the age of the patient and associated diagnoses. ${ }^{5-8,17,18}$ Those with non-valvular atrial fibrillation who have not had a stroke have an untreated risk of embolism of between $0 \%$ and $8.8 \%$ per year. The larger and more recent trials estimate this risk between $2 \%$ and $3 \%$ per year. ${ }^{5,6,18-20}$ Those with non-valvular atrial fibrillation who have had a stroke show a stroke recurrence rate between $9 \%$ and $19 \%$ per year and a mortality rate of $9 \%$ per year if untreated. ${ }^{7,21,22}$

\section{Paroxysmal Atrial Fibrillation}

Paroxysmal atrial fibrillation may be defined as "transient 
Table 1: Consecutive Patients with Stroke or TIA Undergoing Ambulatory Electrocardiography

\begin{tabular}{|c|c|c|c|c|}
\hline Study & Numberof patients & $\begin{array}{l}\text { Number with } \\
\text { atrial fibrillation }\end{array}$ & $\begin{array}{l}\text { Numberwith paroxysmal atrial } \\
\text { fibrillation not detected on initial ECG }\end{array}$ & Comments \\
\hline Koudstaal et al. ${ }^{54}$ & 100 & 4 & $1(1 \%)$ & 2 patients did not have admission ECG \\
\hline Britton et al. ${ }^{55}$ & 100 & 23 & $2(2.6 \%)$ & \\
\hline Richardt et al. ${ }^{56}$ & 135 & $16 *$ & 7 (unable to calculate) & \\
\hline Norris et al. ${ }^{57}$ & 312 & 36 & $15(5.4 \%)$ & \\
\hline Rem et al. ${ }^{58}$ & 184 & 13 & $4(2.3 \%)$ & 2 patients did not have admission ECG \\
\hline Hornig et al. ${ }^{60}$ & 300 & 33 & $10(3.7 \%)$ & $\begin{array}{l}\text { Consecutive patients but only } 87 \% \\
\text { received Holter testing }\end{array}$ \\
\hline
\end{tabular}

*arrhythmias not only atrial fibrillation

atrial fibrillation documented by ECG or Holter at the time of the cerebrovascular event, or in cases of sinus rhythm on baseline ECG, atrial fibrillation documented on ECG or Holter within the previous two years and no successful cardioversion". 22, Dr. P. Koudstaal - personal communication Unfortunately, many articles on paroxysmal atrial fibrillation do not define the entity as precisely, if at all.

The data on stroke risk with paroxysmal atrial fibrillation are conflicting. Insurance data suggest that paroxysmal atrial fibrillation, in the absence of cardiovascular impairment, shows a normal mortality pattern. ${ }^{23}$ Some studies suggest that primary stroke risk in paroxysmal atrial fibrillation is lower than chronic atrial fibrillation, while others, including recent randomized controlled trials of primary stroke prevention suggest a similar risk. ${ }^{12,18,24-31}$ The best estimate of first stroke in those with paroxysmal atrial fibrillation is approximately $2 \%$ per year. ${ }^{33}$ In those with paroxysmal atrial fibrillation, the presence of rheumatic heart disease, increased age, or other cardiac conditions confers an elevated risk for stroke. ${ }^{33-35}$

There are no published data on the risk of recurrent stroke with paroxysmal atrial fibrillation. However, unpublished data from the European Atrial Fibrillation Trial suggest that the risk of recurrent stroke is similar in those with persistent and paroxysmal atrial fibrillation $(20 \%$ vs $18 \%) .{ }^{\text {Dr. P. Koudstaal - personal }}$ communication Although the data are inconclusive, most experts feel that persistent and paroxysmal atrial fibrillation confer similar stroke risks, and recommend equivalent treatment. $5,6,10,12,18,29-$ $32,36,37$

\section{Manoeuvre}

The manoeuvre evaluated in this review is the routine use of ambulatory continuous electrocardiography for the detection of paroxysmal atrial fibrillation in patients with stroke whose 12lead electrocardiogram does not demonstrate atrial fibrillation. An ambulatory continuous electrocardiogram typically records two electrocardiogram leads over a 24- to 48-hour period. Signals can be recorded in a digital or analogue manner. The recorded information is compared with a computer template already classified to detect normal, aberrant supraventricular, or ventricular activity. The investigation is readily available to almost all clinicians, ${ }^{38}$ and is a non-invasive test that poses little or no risk to the patient. Reimbursement of professional fees in Canada for interpretation of 24-hour ambulatory electrocardiography range from approximately $\$ 29-\$ 60 .{ }^{39-43}$

There is little information on the sensitivity, specificity, and cost-effectiveness of ambulatory electrocardiography in symptomatic patients. ${ }^{44}$ Most of the information regarding the technology's ability to detect arrhythmias occurs through analysis of ventricular rather than atrial arrhythmias, which are mostly sought in the evaluation of diagnoses other than stroke. Estimates of ventricular arrhythmia intra- and inter-reader variability can be as high as $10-25 \%$ for the same recording if frequent or complex arrhythmias are present. ${ }^{45}$ In contrast, atrial activity is more difficult to detect than ventricular activity due to its smaller amplitude, and may require special analytical techniques for analysis, although findings are conflicting. ${ }^{44-53}$ Thus there may be less agreement on the interpretation of atrial activity although this has never been formally evaluated.

The yield of ambulatory continuous electrocardiography has been studied in cross-sectional studies of consecutive patients presenting to hospital with either a stroke or transient ischemic attack. Atrial fibrillation may be detected on the initial electrocardiogram in $4 \%$ to $23 \%$ of such patients. ${ }^{54-60}$ In those whose initial electrocardiogram showed normal sinus rhythm, one study found that follow-up 12-lead electrocardiograms on successive days detected atrial fibrillation in an additional $9 \% .{ }^{61}$ Other studies have found that if atrial fibrillation is not detected on initial electrocardiogram, ambulatory continuous electrocardiography can identify paroxysmal atrial fibrillation in $1 \%$ to $5 \%$ of patients (Table 1). ${ }^{54-60}$ Studies of stroke patients referred for ambulatory continuous electrocardiography, rather than consecutive stroke patients, have identified paroxysmal atrial fibrillation in fewer than $2 \%$ of patients. ${ }^{62-65}$ Thus, even in selected cases, the yield of the manoeuvre is quite low.

\section{Effectiveness of Intervention}

There have been no studies that have evaluated the effectiveness of ambulatory continuous electrocardiography followed by anticoagulation of documented atrial fibrillation in preventing recurrent stroke. Some data suggest that ambulatory 
Table 2: Detection and Treatment of Atrial Fibrillation in Patients with Stroke

\begin{tabular}{|c|c|c|c|}
\hline MANOEUVRE & EFFECTIVENESS & LEVELOF EVIDENCE <REFS> & RECOMMENDATION \\
\hline Ambulatory ECG & $\begin{array}{l}\text { The manoeuvre is safe but little is } \\
\text { known about its sensitivity and } \\
\text { specificity. }\end{array}$ & Descriptive studies $<44-47>$ & \\
\hline
\end{tabular}

Anticoagulation if atrial fibrillation detected after stroke

Patients with paroxysmal Unknown 25\% of patients in large randomized atrial fibrillation

controlled trial (I) $<22>$

(no subgroup data provided).
There is fair evidence to generalize from chronic trial fibrillation data and expert opinion to recommend therapy with warfarin $(\mathrm{B})^{*}$

* While direct evidence is lacking, anticoagulation should be strongly considered.

electrocardiography rarely results in a change in management of stroke patients. ${ }^{62,66}$

\section{Effectiveness of Treatment}

The effectiveness of therapy for primary prevention of stroke in atrial fibrillation has been extensively studied. Both aspirin and warfarin have demonstrated benefit in preventing strokes. ${ }^{20,30-32,67}$ A recent meta-analysis of the efficacy of aspirin compared to placebo found a relative risk reduction of $21 \%(95 \%$ confidence interval, 0-38\%) (Level I evidence). ${ }^{68}$ Overall, warfarin had a relative risk reduction of $64 \%$ for major strokes in patients with non-valvular atrial fibrillation (1.4\%/year vs. $0.51 \% /$ year, $\mathrm{p}<0.001)$, with an annual risk of major bleeding incidents of $1.8 \%{ }^{20}$ (Level I evidence). However, some propose that this major bleeding risk is higher and may reflect various patient factors including age, intensity of anticoagulation, past history of bleeding, specific comorbid conditions, and number of

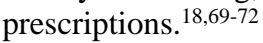

The effectiveness of therapy for secondary prevention of stroke in patients with atrial fibrillation has been addressed in only two randomized controlled trials. A small, inadequately powered nested trial included only 46 individuals with a previous stroke and demonstrated a non-statistically significant reduction in subsequent stroke with warfarin of $60 \%$ (RR 0.40 , 95\% CIs 0.87-1.66). ${ }^{21}$ The larger study included 1007 patients with atrial fibrillation and previous stroke and found the risk reduction for stroke with warfarin compared to placebo was $66 \%$ (hazard ratio 0.34, 95\% CIs 0.20-0.57, NNT 12.5) ${ }^{22}$ (Level I evidence). While the risk of recurrent stroke for those on placebo is about $12 \%$ per year (compared to 4 to $5 \%$ per year in the primary prevention trials), the risk of major or minor bleeding complications with warfarin is about $2.8 \%$ per year (hazard ratio 2.8, 95\% CIs 1.7-4.8). ${ }^{18,19,32,72}$ However, the bleeding risk may have been higher. ${ }^{73,74}$ The trial also compared warfarin to aspirin. Warfarin had a higher efficacy (hazard ratio $0.60,95 \%$ CIs $0.41-$ 0.87 ) but more bleeding complications (hazard ratio $2.8,95 \%$
CIs 1.9-6.0). Of note, the target International Normalized Ratio (INR) of 2.5 to 4.0 exceeded recommended levels and was higher than those used in many comparable trials. ${ }^{32,73}$

Although about $25 \%$ of those in the secondary prevention trials had paroxysmal atrial fibrillation, the data for this subgroup were not presented. Comparable data from a pooled analysis of primary prevention trials found that previous stroke is the strongest predictor of subsequent stroke in those with atrial fibrillation. Further, it detected no difference in stroke risk related to the type of atrial fibrillation..$^{5,6,10,12,18,29-32}$ Hence it seems reasonable to generalize the efficacy of anticoagulation in secondary prevention of stroke to this group.

\section{Interpretation}

\section{Canadian Task Force Recommendations (Table 2)}

The limited available data on the natural history and the effectiveness of treatment for paroxysmal atrial fibrillation precludes the generation of strong recommendations. The diagnosis of atrial fibrillation can frequently be made with a 12lead electrocardiogram and ambulatory continuous electrocardiography often provides added cost with little added benefit. ${ }^{62,66}$ Further, ambulatory continuous electrocardiography may not lead to a change in the management of patients who have other indications for anticoagulation. There is insufficient evidence to recommend for or against the use of ambulatory electrocardiography in all patients with stroke (C Recommendation). There is fair evidence to support the use of warfarin therapy for secondary stroke risk reduction in those with paroxysmal atrial fibrillation (B Recommendation based on generalization from data on chronic atrial fibrillation and expert recommendations).

\section{Recommendations of Others}

The American College of Cardiology/American Heart Association Task Force on the assessment of diagnostic and therapeutic cardiovascular procedures suggests a Class II 
indication ("subject to a divergence of opinion with respect to its utility") for the use of ambulatory electrocardiography in patients with known atrial fibrillation and treated with antiarrhythmic medication. ${ }^{44}$ Neither their recommendations nor other reviews mention the use of ambulatory electrocardiography in the evaluation of strokes. ${ }^{46,47,75}$

Other authors recommend that ambulatory electrocardiographic monitoring be used in patients with suspected occult arrhythmias but should not be used in the initial evaluation of a stroke patient. . $^{5,6,10,66,76-78}$

\section{Research Agenda}

To fully address the question of the most cost-effective method for stroke investigation, an evaluation of approaches or algorithms for the use and sequencing of tests (i.e. 12-lead electrocardiogram then ambulatory continuous electrocardiography) should be undertaken in consecutive stroke patients after proper hypothesis generating exercises. As well, a formal costeffectiveness analysis could be performed after many of these questions are addressed. Further research should also compare both the primary and secondary stroke risks in paroxysmal and chronic atrial fibrillation. Subgroup analyses of the two previous secondary prevention trials would help estimate the risk reduction for those with paroxysmal atrial fibrillation.

\section{Members of the Canadian Task Force on Preventive Health Care}

Chairman: Dr. John W. Feightner, Professor, Department of Family Medicine, The University of Western Ontario, London, Ont.; Past chairman: Dr. Richard Goldbloom, Professor, Department of Pediatrics, Dalhousie University, Halifax, NS. Members: Drs. R. Wayne Elford, Professor and Chair of Research, Department of Family Medicine, University of Calgary, Calgary, Alta.; Michel Labrecque, Associate Professor and Director of Research, Department of Family Medicine and Centre Hospitalier Universitaire de Quebec, Laval University, Quebec, Que.; Harriet MacMillan, Associate Professor, Departments of Psychiatry \& Pediatrics and Centre for Studies of Children at Risk, McMaster University, Hamilton, Ont.; Robin McLeod, Professor, Department of Surgery, Mount Sinai Hospital and University of Toronto, Toronto, Ont.; Jean-Marie Moutquin, Professor, Department of Obstetrics and Gynecology and Research Centre Saint-Francois d'Assise, Laval University, Quebec, Que.; Christopher Patterson, Professor and Head, Division of Geriatric Medicine, Department of Medicine, McMaster University, Hamilton, Ont.; Elaine E.L. Wang, Associate Professor, Departments of Pediatrics and of Public Health Sciences, Faculty of Medicine, University of Toronto, Toronto, Ont. Resource people: Ms. Nadine Wathen, Coordinator, Canadian Task Force on Preventive Health Care, Department of Family Medicine, The University of Western Ontario, London, Ont. and Mr. Tim Pauley, Research Assistant, Canadian Task Force on Preventive Health Care, Department of Family Medicine, The University of Western Ontario, London, Ont.

\section{ACKNOWLEDGEMENTS}

We thank Dr. Bruce Reeder, University of Saskatchewan, Saskatoon, Saskatchewan, and Dr. Andreas Laupacis, Loeb Research Institute, Ottawa, Ontario, for reviewing a draft form of this report. The views expressed in this report are those of the authors and the Task Force and do not necessarily reflect the positions of reviewers.

\section{SUPPORT}

Dr. Bell holds a Medical Research Council of Canada Research Fellowship. Dr. Kapral held a Research Fellowship from the Heart and Stroke Foundation of Canada at the time of authorship.

\section{REFERENCES}

1. Statistics Canada, Health Canada, Heart and Stroke Foundation of Canada, editors. Heart Disease and Stroke in Canada 1997.

2. Statistics Canada. Causes of death, 1993. Cat. 84-208 (Annual).

3. Bonita R. Epidemiology of stroke. Lancet 1992;339:342-347.

4.. Moore R, Mao Y, Zhang J, Clake K. Economic burden of illness in Canada, 1993. Catalogue No H21-136/1993E, Canadian Public Health Association, 1997 (http://www.hwc.ca/hpb/lcdc/publicat/ burden/index.html)

5. Cerebral Embolism Task Force. Cardiogenic brain embolism: the second report of the Cerebral Embolism Task Force. Arch Neurol 1989;46:727-743.

6. Sherman DG, Dyken ML, Fisher M, et al. Cerebral embolism. Chest 1986;89 (suppl):82S-98S.

7. Sandercock P, Bamford J, Dennis M, et al. Atrial fibrillation and stroke: prevalence in different types of stroke and influence on early and long term prognosis (Oxfordshire community stroke project). Br Med J 1992;305:1460-5.

8. Broderick JP, Phillips SJ, O'Fallon M, Frye RL, Whisnant JP. Relationship of cardiac disease to stroke occurrence, recurrence, and mortality. Stroke 1992;23:1250-1256.

9. Phillips SJ, Whisnant JP, O'Fallon WM, Frye RL. Prevalence of cardiovascular disease and diabetes mellitus in residents of Rochester, Minnesota. Mayo Clin Proc 1990;65:344-359.

10. Cerebral Embolism Task Force. Cardiogenic brain embolism. Arch Neurol 1986;43:71-84.

11. Bharucha NE, Wolf PA, Kannel WB, et al. Epidemiological study of cerebral embolism: the Framingham Study, abstracted. Ann Neurol 1981;10:105.

12. Sherman DG, Goldman L, Whiting RB, et al. Thromboembolism in patients with atrial fibrillation. Arch Neurol 1984;708-710.

13. Lin H-J, Wolf PA, Benjamin EJ, et al. Newly diagnosed atrial fibrillation and acute stroke: the Framingham Study. Stroke 1995;26:1527-1530.

14. Selzer A. Atrial fibrillation revisited. N Engl J Med 1982;306:10441045.

15. Bougousslavsky J, Van Melle G, Regli F. The Lausanne Stroke Registry: analysis of 1,000 consecutive patients with first stroke. Stroke 1988;19:1083-1092.

16. Woolf SH, Battista RN, Anderson GM, Logan AG, Wang E and other members of the Canadian Task Force on the Periodic Health Examination. Assessing the clinical effectiveness of preventive manoeuvers: analytic principles and systematic methods in reviewing evidence and developing clinical practice recommendations. J Clin Epidemiol 1990; 43(9): 891905.

17. The Stroke Prevention in Atrial Fibrillation Investigators. Predictors of thromboembolism in atrial fibrillation: I. Clinical features of patients at risk. Ann Int Med 1992;116:1-5.

18. Atrial Fibrillation Investigators. Risk factors for stroke and efficacy of antithrombotic therapy in atrial fibrillation. Arch Intern Med 1994;154:1449-1457.

19. The SPAF III Writing Committee for the Stroke Prevention in Atrial Fibrillation Investigators. Patients with non-valvular atrial fibrillation at low risk of stroke during treatment with aspirin. JAMA1998;279:1273-1277.

20. Green CJ, Hadorn DC, Bassett K, Kazanjian A. Anticoagulation in 
chronic non-valvular atrial fibrillation: a critical appraisal and meta-analysis. Can J Cardiol 1997;13:811-815.

21. Ezekowitz MD, Bridgers SL, James KE, et al. Warfarin in the prevention of stroke associated with non-rheumatic atrial fibrillation. N Engl J Med 1992;327:1406-1412.

22. EAFT Study Group. Secondary prevention in non-rheumatic atrial fibrillation after transient ischemic attack or minor stroke. Lancet 1993;342:1255-1262.

23. Gajewski J, Singer RB. Mortality in an insured population with atrial fibrillation. JAMA1981;245:1540-1544.

24. Kannel WB, Abbot RD, Savage DD, McNamara PM. Coronary heart disease and atrial fibrillation: the Framingham Study. Am Heart J 1983;106:389-396.

25. Treseder AS, Sastry BSD, Thomas TPL, et al. Atrial fibrillation and stroke in elderly hospitalized patients. Age and Ageing 1986;15:89-92.

26. Takahashi N, Seki A, Imataka K, Fujii J. Clinical features of paroxysmal atrial fibrillation. An observation of 94 patients. Jpn Heart J 1981;22:143-149.

27. Shimomura $K$, Ohe $T$, Uehara $S$ et al. Significance of atrial fibrillation as a precursor of embolism. Am J Cardiol 1989;63:1405-1407.

28. Wiener I, Hafner R, Nicolai M, Lyons H. Clinical and echocardiographic correlates of systemic embolization in nonrheumatic atrial fibrillation. Am J Cardiol 1987;59:177.

29. Roy D, Marchand E, Gagne P, et al. Usefulness of anticoagulant therapy in the prevention of embolic complications of atrial fibrillation. Am Heart J 1986;112:1039-1043.

30. Stroke Prevention in Atrial Fibrillation Investigators. Stroke prevention in atrial fibrillation study: final results. Circulation 1991;84:527-539.

31. Boston Area Anticoagulation Trial for Atrial Fibrillation Investigators. Effect of low-dose warfarin on the risk of stroke in patients with non-rheumatic atrial fibrillation. N Engl J Med 1990;323:1506-1511.

32. Laupacis A, Albers GW, Dalen JE, et al. Antithrombotic therapy in atrial fibrillation. Chest 1995;108 (suppl):352-359S.

33. Petersen Pand Godtfredsen J. Embolic complications in paroxysmal atrial fibrillation. Stroke 1986;17:622-626.

34. Auguste H, Fortin BA, Isner JM. Should patients with paroxysmal atrial fibrillation receive prophylactic anticoagulation? J Am Coll Cardiol 1983;1:704.

35. Corbalan R, Arriagada D, Braun S, et al. Risk factors for systemic embolism in patients with paroxysmal atrial fibrillation. Am Heart J 1992;124:149-153.

36. Lip GYH. Does paroxysmal atrial fibrillation confer a paroxysmal thromboembolic risk? Lancet 1997;349:1565-1566.

37. Lip GYH, Lowe GDO. ABC of atrial fibrillation. Antithrombotic therapy for atrial fibrillation. Br Med J 1996;312:45-49.

38. Goldstein LB, Bonito AJ, Matchar DB, et al. US national survey of physician practices for the secondary and tertiary prevention of ischemic stroke: design, service availability, and common practices. Stroke 1995;26:1607-1615.

39. British Columbia Medical Association Guide to Fees. Page 103. April 1995.

40. Manitoba Health Services Insurance Plan - Physician's manual. Page H-1. April 1995.

41. Medical Specialists' Manual Health Insurance Plan. Page C-10. December 1996.

42. Alberta Health Care Insurance Plan Schedule of Medical Discipline Benefits. Page 10. January 1997.

43. Ontario Ministry of Health Schedule of Benefits. Page J-6. February 1998.

44. Knoebel SB, et al. American College of Cardiology/American Heart
Association. Guidelines for ambulatory electrocardiography. JACC 1989;13:249-258.

45. Pratt CM, Eaton T, Francis M, Pacifico A. Ambulatory electrocardiographic recordings: the Holter monitor. Curr Probl Cardiol 1988;13:521-586.

46. DiMarco JP, Philbrick JT. Use of ambulatory electrocardiographic (Holter) monitoring. Ann Intern Med 1990;113:53-68.

47. Zimetbaum PJ and Josephson ME. The evolving role of ambulatory arrhythmia monitoring in general practice. Ann Intern Med 1999; 130:848-856.

48. Murakami Y, Okamoto M, Nakayama R. Atrial late potential by $\mathrm{P}$ wave-triggered signal-averaged electrocardiogram and paroxysmal atrial fibrillation. Nippon Rinsho 1995;53:489-495.

49. Stafford PJ, Cooper J, Fothergill J, et al. Reproducibility of the signal-averaged $\mathrm{P}$ wave: time and frequency domain analysis. Heart 1997;77:412-416.

50. Michelucci A, Padeletti L, Chelucci A, et al. Influence of age, lead axis, frequency of arrhythmic episodes, and atrial dimensions on $\mathrm{P}$ wave triggered SAECG in patients with lone paroxysmal atrial fibrillation. Pacing Clin Electrophysiol 1996;19:758-767.

51. Yamaguchi I, Kuga K, Sugishita Y, Ito I. The signal-averaged electrocardiogram as a screening test for occurrence of paroxysmal atrial fibrillation. J Am Coll Cardiol 1988;11:116A.

52. Engel TR, Vallone N, Windle J. Signal-averaged electrocardiograms in patients with atrial fibrillation or flutter. Am Heart J 1988;115:592-597.

53. Fukunami M, Yamada T, Ohmori M, et al. Detection of patients at risk for paroxysmal atrial fibrillation during sinus rhythm by $\mathrm{P}$ wave-triggered signal-averaged electrocardiogram. Circulation 1991;83:162-169.

54. Koudstaal PJ, van Gijn J, Klootwuk APJ, et al. Holter monitoring in patients with transient and focal ischemic attacks of the brain. Stroke 1986;17:192-195.

55. Britton M, de Faire U, Helmers C, et al. Arrhythmias in patients with acute cerebrovascular disease. Acta Med Scand 1979;205:425-428.

56. Richardt G, Ensle G, Schwarz F, et al. Diagnostik kardialer Ursachen zerebraler Embolien: Beitrag von 2D-Echokardiographie und Langzeit-EKG. Z Kardiol 1989;78:598-601.

57. Norris JW, Froggatt GM, Hachinski VC. Cardiac arrhythmias in acute stroke. Stroke 1978;9:392-396.

58. Rem JA, Hachinski VC, Boughner DR, Barnett HJM. Value of cardiac monitoring and echocardiography in TIA and stroke patients. Stroke 1985;16:950-956.

59. Mikolich JR, Jacobs WC, Fletcher GF. Cardiac arrhythmias in patients with acute cerebrovascular accidents. JAMA 1981;246:1314-1317.

60. Hornig CR, Haberbosch W, Lammers C, et al. Specific cardiological evaluation after focal cerebral ischemia. Acta Neurol Scand 1996;93:297-302.

61. Lindgren A, Roijer A, Norrving B, et al. Carotid artery and heart disease in subtypes of cerebral infarction. Stroke 1994;25:23562362.

62. Come PC, Riley MF, Bivas NK. Roles of echocardiography and arrhythmia monitoring in the evaluation of patients with suspected systemic embolism. Ann Neurol 1983;13:527-531.

63. Tonet JL, Frank R, Ducardonnet A, et al. L'enregistrement de Holter dans les acidents ischemiques cerebraux. Nouv. Presse Med. 1981;10:2491-2494.

64. Kessler DK, Kessler KM. Is ambulatory electrocardiography useful in the evaluation of patients with recent stroke? Chest 1995;107:916-918.

65. Bogousslavsky J, Hachinski VC, Boughner DR, et al. Cardiac and arterial lesions in carotid transient ischemic attacks. Arch Neurol 1986;43:223-228. 
66. Kessler DK, Kessler KM, Myerburg RJ. Ambulatory electrocardiography: a cost per management decision analysis. Arch Intern Med 1995;155:165-169.

67. Connoly SJ, Laupacis A, Gent M, et al. Canadian Atrial Fibrillation Anticoagulation (CAFA) study. J Am Coll Cardiol 1991;18:349355.

68. The Atrial Fibrillation Investigators. The efficacy of aspirin in patients with atrial fibrillation: analysis of pooled data from 3 randomized trials. Arch Intern Med 1997;157:1237-1240.

69. Laupacis A. Re: CJ Green, DC Hadorn, K Bassett, A Kazanjian. Anticoagulation in chronic nonvalvular atrial fibrillation: a critical appraisal and meta-analysis. 1997;13:811-5. Can J Cardiol. 1998; 14(5): 659,662-663.

70. Mant MJ. Re: CJ Green, DC Hadorn, K Bassett, A Kazanjian. Anticoagulation in chronic non-valvular atrial fibrillation: a critical appraisal and meta-analysis. 1997;13:811-815. Can J Cardiol. 1998; 14(5): 663.

71. Levine MN, Hirsh J, Landefeld S, Raskob G. Hemorrhagic complications of anticoagulant treatment. Chest 1992;102 (suppl): 352S-363S.

72. The Stroke Prevention in Atrial Fibrillation Investigators. Bleeding during antithrombotic therapy in patients with atrial fibrillation. Arch Intern Med 1996;156:409-416.

73. Albers GW. Atrial fibrillation and stroke: three new studies, three remaining questions. Arch Intern Med 1994;154:1443-1448.

74. The European Atrial Fibrillation Trial Study Group. Optimal oral anticoagulant therapy in patients with nonrheumatic atrial fibrillation and recent cerebral ischemia. N Engl J Med 1995;333:5-10.

75. Harrison DC, Fitzgerald JW, Winkle RA. Ambulatory electrocardiography for diagnosis and treatment of cardiac arrhythmias. N Engl J Med 1976;294:373-380.

76. Hankey GJ, Warlow CP. Cost-effective investigation of patients with suspected transient ischaemic attacks. J Neurol Neurosurg Psychiatry. 1992;55:171-176.

77. Brown Jr RD, Evans BA, Wiebers DO, et al. Transient ischemic attack and minor ischemic stroke: an algorithm for evaluation and treatment. Mayo Clin Proc 1994;69:1027-1039.

78. Feinberg WM, Albers GW, Barnett HJM, et al. Guidelines for the management of transient ischemic attacks. Stroke 1994;25:1320-1335.

\section{APPENDIX 1}

Canadian Task Force on Preventive Health Care Levels of Evidence and Grades of Recommendations ${ }^{13}$

\section{Quality of Published Evidence}

I Evidence from at least one properly randomized controlled trial (RCT).

II-1 Evidence from well-designed controlled trials without randomization.

II-2 Evidence from well-designed cohort or case-control analytic studies, preferably from more than one centre or research group.

II-3 Evidence from comparisons between times or places with or without the intervention. Dramatic results in uncontrolled experiments could also be included here.

III Opinions of respected authorities, based on clinical experience, descriptive studies or reports of expert committees.

\section{Grades of Recommendations}

A Good evidence to support the recommendation that the condition be specifically considered in a periodic health examination (PHE).

B Fair evidence to support the recommendation that the condition be specifically considered in a PHE.

$\mathrm{C}$ Insufficient evidence regarding inclusion or exclusion of the condition in a PHE, but recommendations may be made on other grounds.

D Fair evidence to support the recommendation that the condition be specifically excluded from consideration in a PHE.

E Good evidence to support the recommendation that the condition be specifically excluded from consideration in a PHE 